\title{
Instrumentos de avaliação cognitiva no ensino odontológico: reflexões sobre uma experiência
}

\author{
Alana Gail Lopes*; Laísa Neves Gregório**; Antônio Marcio Lima Ferraz Júnior***; Marcelo Tarcísio \\ Martins***; Rodrigo Guerra de Oliveira****; Rinaldo Henrique Aguilar da Silva*****; Fabiana \\ Aparecida Mayrink de Oliveira***
}

* Mestranda em Odontologia, ênfase em Clínica Odontológica, UFJF

** Graduada em Odontologia, FCMS/JF

*** Mestre, Professor(a) do curso de Odontologia, FCMS/JF

$* * * *$

Doutor, Coordenador do curso de Odontologia, FCMS/JF

Doutor, Professor da Faculdade de Medicina de Marília

Recebido em 19/03/2019. Aprovado em 24/10/2019.

\begin{abstract}
RESUMO
A avaliação cognitiva do desempenho acadêmico no curso de Odontologia tem sido feita de forma pouco padronizada, sem obedecer a uma ordem taxonômica de objetivos educacionais, gerando uma percepção distorcida da competência adquirida pelo aluno. Assim, apresentam-se os instrumentos de avaliação utilizados no curso de Odontologia da Faculdade de Ciências Médicas e da Saúde de Juiz de Fora (FCMS/JF) para provocar reflexões acerca da dinâmica das avaliações. Para tanto, o Núcleo de Avaliação da Odontologia (NAO) elaborou instrumentos avaliativos para construção de provas estruturadas (seis questões discursivas, em três diferentes níveis de taxonomia), um checklist para verificação das avaliações pelo NAO antes de ser entregue aos estudantes e a meta-avaliação, quando os discentes avaliam o conteúdo da prova, sua objetividade e clareza. Os três instrumentos, apresentados neste estudo, formam entre si uma dinâmica avaliativa que se repete duas vezes por semestre letivo, visando à melhoria do processo avaliativo dos educandos e, consequentemente, uma aprendizagem significativa. Desta forma, acredita-se que esses instrumentos avaliativos, dentro da dinâmica semestral, podem contribuir para uma melhor percepção da competência cognitiva adquirida pelos acadêmicos de Odontologia.
\end{abstract}

Descritores: Ensino. Avaliação Institucional. Odontologia.

\section{INTRODUÇÃO}

As Diretrizes Curriculares Nacionais (DCN) do curso de graduação em Odontologia marcaram, desde sua efetivação no ano de 2002, um novo conceito sobre a formação do cirurgião-dentista ${ }^{1}$. Nesse contexto, diversos cursos passaram a buscar propostas em que a prática diária dos estudantes fosse vinculada ao desenvolvimento de 
competências profissionais, e não mais marcada pela fragmentação de conteúdos².

Desta forma, metodologias ativas de ensino passaram a integrar cada vez mais a "grade tradicional" do curso, e nesta o "professor" deixa de ter a função de proferir ou de ensinar e passa a ser um facilitador do processo de aquisição do conhecimento, enquanto o "aluno" recebe denominações que remetem ao contexto dinâmico e construtivo, o que influencia positivamente tanto educadores quanto educandos $3,4,5$. Dentre as metodologias ativas estão o Ensino Baseado em Problemas (PBL), que trabalha com atividades divididas tipicamente em etapas com pequenos grupos de estudantes; a Problematização, que se baseia em análises de problemas de uma população que posteriormente serão transformados com base nos estudos levantados; a Aprendizagem Baseada em Equipes (ABE), na qual os discentes são divididos em grupos de cinco a oito participantes para discutir um caso clínico e chegarem a um consenso de resposta, que será analisada diante de toda turma posteriormente ${ }^{4}$.

Logo, o professor enfrenta o desafio de quebrar paradigmas, buscando desenvolver a capacidade do educando de aprender a aprender, aplicar o conhecimento teórico obtido e trabalhar em equipe ${ }^{6-8}$. Entretanto, grande parte desses docentes adquiriu em sua pós-graduação uma formação puramente técnica e especialista ${ }^{9}$, o que implica em ensino altamente depositário de conteúdos, os quais rapidamente tornam-se obsoletos em virtude da dinâmica modificação da realidade ${ }^{10}$. No momento em que o estudante se depara com os problemas dessa realidade, na vida profissional, torna-se incapaz de resolvê-los, procurando a solução nas especialidades, perpetuando o paradigma da formação centrada em técnicas e especializações do ensino superior em Odontologia, contrariando a demanda da sociedade e as orientações das DCN quanto ao perfil generalista $^{9,11}$. O avanço está em metodologias que integrem os conteúdos, centralizem o estudante no processo de ensino-aprendizagem, dando autonomia no desenvolvimento das competências profissionais; posicionando o professor como um intermediador, com abrangência holística, numa perspectiva de entendimento humano como um ser biopsicossocial, que é, enfim, a proposta das metodologias ativas de ensino ${ }^{6}$. Porém, para que o professor passe por essa transformação, que consequentemente transformará o acadêmico, são necessários alguns pilares: reflexão, intensa e profunda capacitação e motivação.

Entretanto, percebe-se que a utilização de métodos ativos de educação na Odontologia ainda se justapõe ao modelo tradicional de ensino, constituindo um modelo híbrido no ensinar; consequente da formação docente, que ensina de forma tradicional (o professor no centro do processo) para uma geração de estudantes que possuem outras dinâmicas no processo de aprendizagem, o que gera grande dificuldade na avaliação. Afinal, como "medir" o ganho cognitivo do acadêmico senão por meio de provas? A avaliação traz em sua essência uma concepção diagnóstica, que permite verificar se objetivos cognitivos foram atingidos, se o avaliado revelou seu mérito e seu valor, se o objeto avaliado atende aos critérios estabelecidos pelos avaliadores ou pelos interessados nos resultados da avaliação ${ }^{12}$.

Geralmente as avaliações são compostas de questões sem algum padrão, com perguntas de caráter técnico e direto; o que leva a uma aprendizagem mecânica ou memorizadora. Logo, na educação, é fundamental decidir e definir os objetivos de aprendizagem de modo a organizar e estruturar a forma como as avaliações serão feitas, possibilitando mudanças de pensamentos, ações e condutas $^{13}$.

Nesse cenário, a Taxonomia de Objetivos Educacionais, popularizada como Taxonomia de Bloom, possibilita a elaboração de uma prova na qual a medição dos resultados da aprendizagem obedeça a uma sequência progressiva de objetivos educacionais ordenados hierarquicamente, do mais 
simples ao mais avançado. Os níveis dessa taxonomia são conhecimento, compreensão, aplicação, análise, síntese e avaliação ${ }^{14}$. Desta forma, a capacidade de lembrar do educando corresponde ao menor nível taxonômico, e a capacidade de criar corresponde ao nível mais complexo na taxonomia. Assim, os educadores ajudarão seus discentes, de forma estruturada e consciente, a adquirir competências específicas a partir da percepção da necessidade de dominar habilidades mais simples para, posteriormente, dominar as mais complexas ${ }^{4,13}$.

Para tanto, a avaliação deve apresentar-se de forma sistemática, que não tem fim em si mesma, é alvo de processo contínuo e regular de aprimoramento, sendo frequentemente necessária a avaliação da avaliação, denominada metaavaliação ${ }^{15}$. Esta representa um instrumento avaliador, no qual o docente conseguirá uma percepção dos estudantes em relação às provas realizadas. Com isso, o docente que teve sua prova avaliada por seus educandos poderá marcar os pontos em que precisa melhorar, e com isso implementar mudanças para que essa melhora, de fato, aconteça ${ }^{13}$.

Além da meta-avaliação, outro instrumento capaz de registrar o desempenho, comportamentos ou a demonstração de apropriação de conteúdos é a lista de verificação ou checklist. Este pode ser elaborado como uma lista única, construída por um professor, geralmente tendo como referencial a atividade realizada pelo estudante ${ }^{16,17}$.

Desta forma, relata-se a experiência do curso de graduação em Odontologia da Faculdade de Ciências Médicas e da Saúde de Juiz de Fora (FCMS/JF), apresentando-se os três instrumentos utilizados (prova estruturada, checklist avaliativo e meta-avaliação) à comunidade científica odontológica, com o intuito de embasar discussões sobre a padronização dos modelos avaliativos em Odontologia.

\section{RELATO DE EXPERIÊNCIA}

Desde 2013 a FCMS/JF vem estruturando as avaliações cognitivas do curso de Odontologia de acordo com as DCN e projeto pedagógico do curso, elaborando questões discursivas critérioreferenciadas, que abrangem todos os níveis de complexidade da Taxonomia de Bloom. Para tanto, os professores passaram por uma série de capacitações e oficinas conduzidas por docente competente na área de ensino em saúde, sobre o novo sistema de avaliação, como elaborar questões discursivas e de múltipla-escolha e sobre taxonomia de Bloom. Um longo processo iniciou-se com os docentes da instituição, que responderam primeiramente com negação, desconfiança e medo do novo, posteriormente com aquisição do conhecimento de forma individual emergindo a reflexão e, após sucessivas aproximações, ao final, a maioria reagiu com aceitação. A partir desse momento o novo modelo de avalição foi considerado obrigatório para todos os docentes desta instituição privada.

Assim, entendeu-se que para assegurar a aprendizagem de maneira mais consistente e fidedigna é importante verificar a estrutura da prova quanto aos tipos de perguntas formuladas, a qualidade que se exige, as respostas que se espera obter conforme o conteúdo das perguntas ou problemas que são formulados ${ }^{16}$. Para tanto, o Núcleo de Avaliação da Odontologia (NAO) elaborou um instrumento capaz de verificar a prova, denominado checklist avaliativo. O NAO é composto por professores previamente capacitados, com regime de trabalho parcial ou integral, que participam de outras atividades docentes na instituição. O checklist aborda desde a forma como o docente organiza suas questões, como por exemplo, as áreas de conhecimento que utilizou ao formular a mesma, bem como seu valor e se a questão foi contextualizada, até a forma como foi escrita, se estava dentro do nível taxonômico e com linguagem adequada. 
Somente o checklist da prova realizado por professores do NAO não garante a qualidade, por isso a participação ativa dos estudantes também é de extrema importância no processo, favorecendo a construção do conhecimento conjunta ${ }^{1}$. Para tanto, a percepção do acadêmico sobre a prova é fundamental para que haja um feedback construtivo. Assim sendo, foi elaborado outro instrumento para verificar a prova, a meta-avaliação. Este é preenchido pelos discentes após a realização de cada prova e tem a função de auxiliar os professores no aprimoramento de seus pontos fortes e melhorar suas fragilidades quando se trata da elaboração dessas avaliações.

Para que a meta-avaliação agregue valor ao ensino-aprendizagem, os acadêmicos são capacitados a respondê-la, principalmente no primeiro período, quando estão conhecendo todos os processos de ensino do curso. Membros do NAO e professores engajados no processo explicam sobre a avaliação padronizada, a metaavaliação e a devolutiva. O manual do acadêmico é entregue impresso e também disponibilizado no sítio web do curso, com todas essas informações. A cada semestre esses conceitos são reforçados com sucessivas aproximações.

Os três instrumentos avaliativos criados pelo NAO apresentados neste artigo são a avaliação cognitiva padronizada de acordo com a taxonomia de objetivos educacionais, o checklist avaliativo e a meta-avaliação. O primeiro deles, a avaliação cognitiva teórica aplicada, segue um padrão de formatação e confecção critério-referenciada, embasada nos princípios da Taxonomia de Bloom. É construída com seis questões discursivas obrigatórias, sendo a primeira delas com contexto e enunciados que remetem a alta taxonomia, contendo quinze linhas numeradas para resposta. As duas questões seguintes são de média taxonomia, e possuem oito linhas para resposta. As três últimas questões são consideradas de baixa taxonomia, e apresentam duas linhas para a resposta, de caráter mais objetivo. Caso o professor da disciplina julgue necessário, poderá acrescentar mais questões, sendo essas de múltipla escolha. As questões devem conter área de conhecimento, valor, gabarito e referências bibliográficas.

O segundo instrumento, o checklist criado pelo NAO para a verificação da avaliação previamente à sua aplicação, aborda treze itens, cujas respostas possíveis são "sim", "não" ou "em parte". As taxonomias, gabaritos coerentes com os enunciados e referências são exemplos de itens avaliados (figura 1). O checklist é importante para nortear os professores quanto à sua avaliação e para manter a padronização, o que beneficia o estudante, pois não há surpresa em relação ao formato da avaliação.

Por fim, a meta-avaliação é abordada na forma de quatro itens, que são respondidos pelos estudantes como "satisfatório" ou "insatisfatório" (figura 2). O conteúdo da prova, quantidade de linhas por questão, objetividade e clareza são os itens desse instrumento. Nele também existe um espaço para críticas e sugestões particulares, relacionadas à avaliação realizada.

Os três instrumentos construídos são utilizados numa dinâmica avaliativa do curso, que se inicia pela elaboração das avaliações pelos professores, respeitando o modelo padrão da instituição, em seguida o NAO as verifica utilizando o checklist e oportunamente sugere mudanças aos professores, no sentido de adequação ao padrão. Na sequência as avaliações são aplicadas na semana de provas pré-definida no calendário letivo. Simultaneamente, o estudante recebe a meta-avaliação, que deverá ser preenchida e devolvida após o término da prova. Com a metaavaliação em mãos, o NAO novamente atua analisando os resultados para, então, dar feedback ao professor, melhorando assim a qualidade da avaliação e estabelecendo padrões de correção. Assim que o professor corrigiu as provas ocorre um momento em sala de aula, denominado devolutiva da prova, quando estas são entregues aos alunos e 


\begin{tabular}{|c|c|c|c|}
\hline \multicolumn{4}{|c|}{ CHECKLIST de $A_{\text {__ }}$ __ semestre de ___ ano } \\
\hline \multicolumn{4}{|l|}{ Professor: } \\
\hline Disciplina: & \multicolumn{3}{|c|}{ Periodo: } \\
\hline \multicolumn{4}{|l|}{ Curso: } \\
\hline & Sim & Não & $\begin{array}{c}\text { Em } \\
\text { partes }\end{array}$ \\
\hline \multicolumn{4}{|c|}{ Preencha o número das questões referentes a: Sim / Não ou Em parte } \\
\hline \multicolumn{4}{|c|}{ O enunciado contém apenas dados e informações essenciais } \\
\hline \multicolumn{4}{|l|}{ Utilizou os verbos de acordo com a taxonomia } \\
\hline \multicolumn{4}{|c|}{ Apresenta os conteúdos de forma contextualizada } \\
\hline \multicolumn{4}{|l|}{ Está com nível e linguagem adequados } \\
\hline \multicolumn{4}{|l|}{ As questões apresentam comandos claros } \\
\hline \multicolumn{4}{|c|}{ Apresenta questões que possibilitam o uso do pensamento lógico } \\
\hline \multicolumn{4}{|l|}{ O enunciado está muito extenso } \\
\hline \multicolumn{4}{|l|}{ Existe coerência entre o gabarito e a pergunta } \\
\hline \multicolumn{4}{|l|}{ Estabeleceu o valor de cada questão } \\
\hline \multicolumn{4}{|l|}{ Inseriu a área de conhecimento em cada questão } \\
\hline \multicolumn{4}{|l|}{ Cada questão possui gabarito } \\
\hline \multicolumn{4}{|l|}{ A prova está com a bibliografia } \\
\hline Está no modelo padronizado pela Instituição & & & \\
\hline
\end{tabular}

Figura 1. Checklist da avaliação entregue ao professor, para ajustes ao modelo avaliativo padronizado da instituição

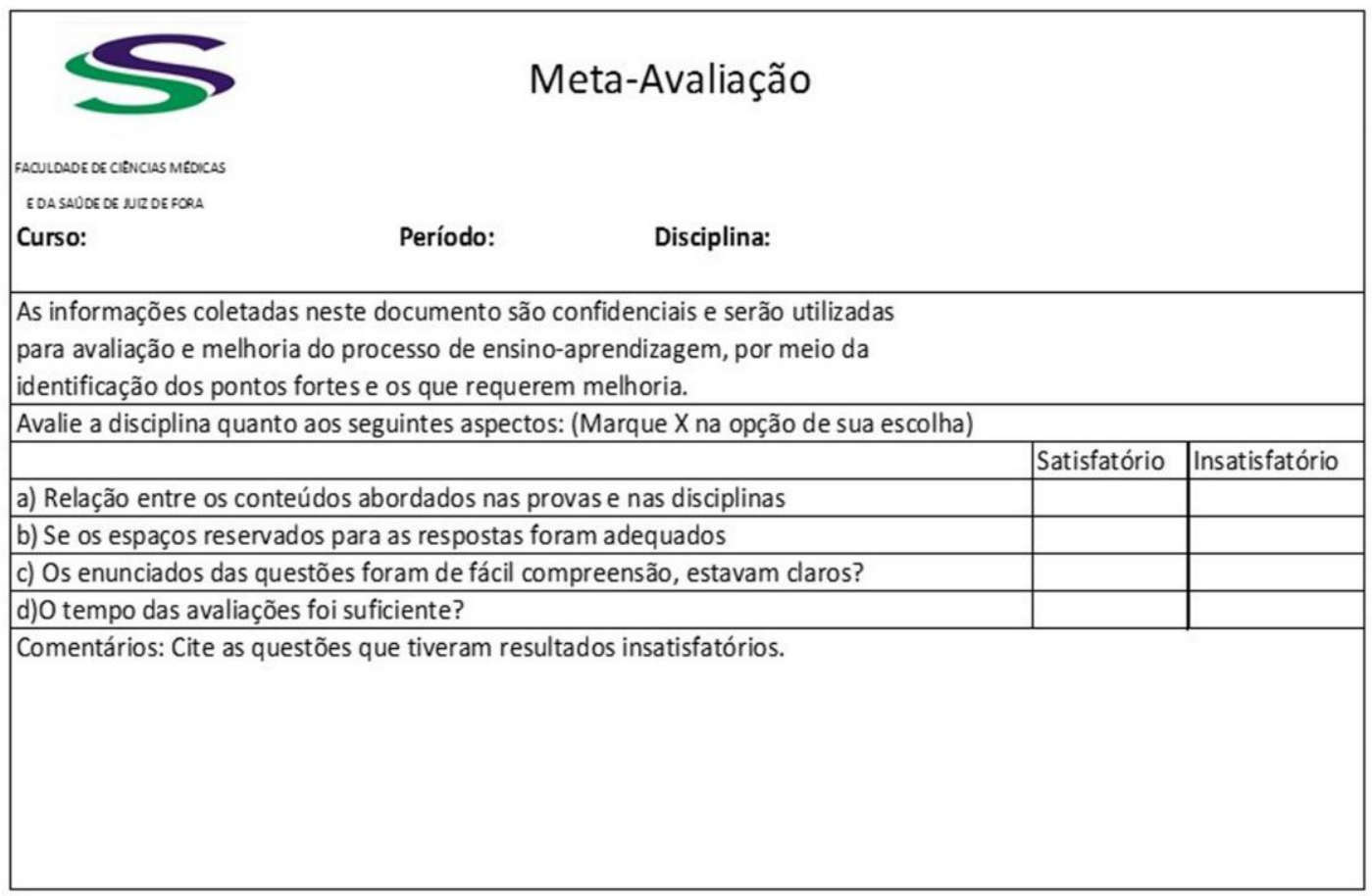

Figura 2. Instrumento de meta-avaliação, entregue aos estudantes no momento da realização da prova por disciplina 
o gabarito é apresentado, constituindo mais um momento de aprendizagem e reflexão do processo avaliativo.

Entretanto, a devolutiva não é momento de revisão de prova, caso o estudante julgue que a prova não foi corrigida adequadamente, deverá agendar junto a secretária a revisão. Este ciclo repete-se duas vezes por semestre letivo, sempre no sentido de fortalecimento do processo avaliativo, pois o professor passa ter em mãos suas fortalezas e fragilidades, podendo trabalhá-las com apoio do NAO (figura 3).

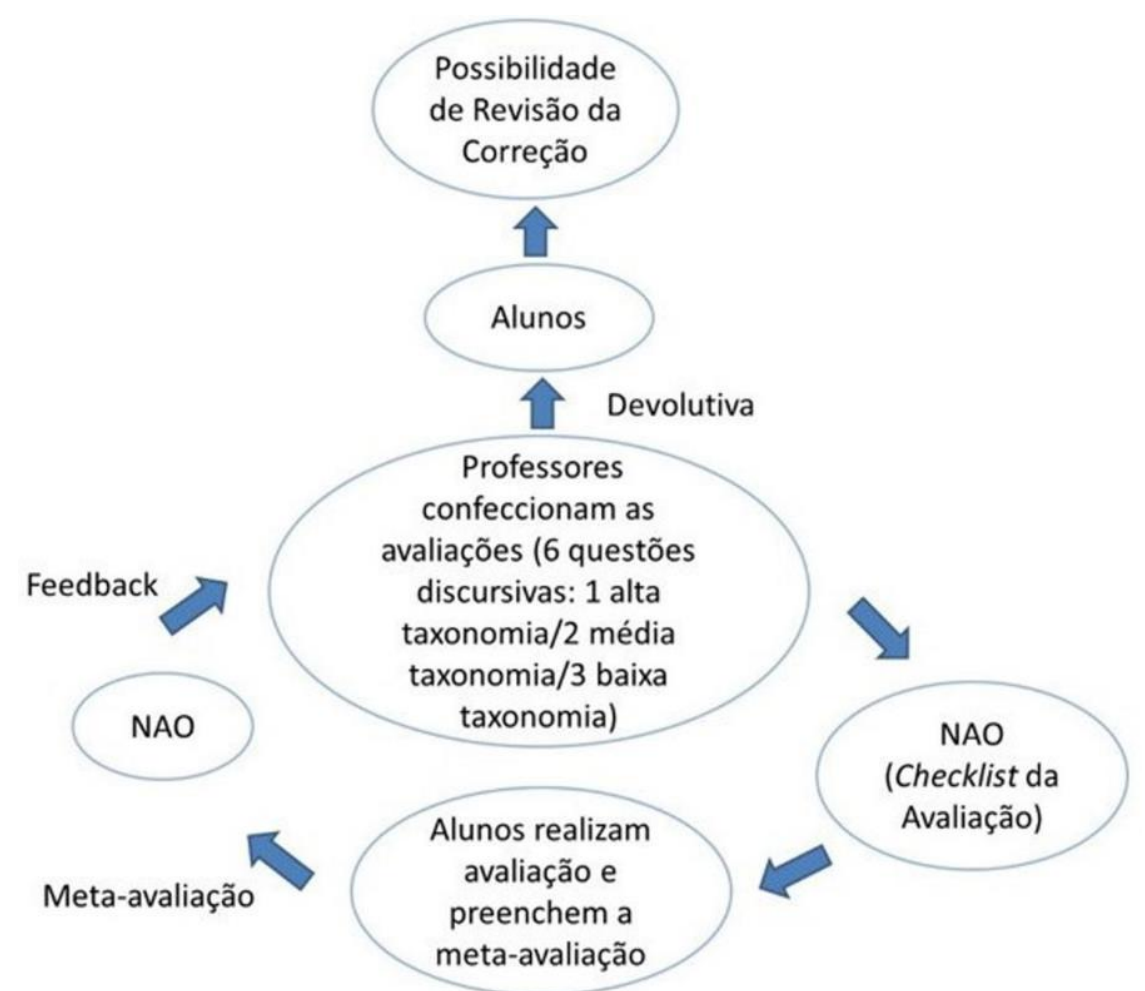

Figura 3. Dinâmica do ciclo avaliativo do curso

Apesar de estudos demonstrarem que as avaliações convencionais não são capazes de "medir" o saber dos educandos, esta afirmação é ainda difícil de ser apreendida, tanto por parte dos docentes e discentes, quanto por parte dos pais e da própria sociedade. Nos últimos anos, a credibilidade em relação às medidas, resumidas nas conhecidas notas decorrentes dos processos avaliativos em diversos níveis educacionais parece ter conquistado elevados patamares, seja em provas e disputas internas das instituições, seja na forma de exames como o concurso vestibular ou avaliações no âmbito nacional (Exame Nacional do Ensino Médio/Enem,
Sistema Nacional de Avaliação da Educação Básica/Saeb e Exame Nacional de Desempenho dos Estudantes/Enade). Estudantes, professores e responsáveis têm sido reféns das medidas para qualquer tomada de decisão diante do sistema educacional brasileiro ${ }^{18}$.

Segundo a comissão do Conselho Nacional de Educação/Câmara de Educação Superior (CNE/CES) do ano de 2002, na resolução ${ }^{\circ} 3$, das DCN dos cursos de graduação, o curso de Odontologia deve apresentar um projeto pedagógico centrado no estudante como sujeito de sua aprendizagem e apoiado no professor como facilitador desse processo. $\mathrm{O}$ discente deve 
ter uma formação de caráter generalista, humano, reflexivo e crítico, de forma que consiga atuar em todos os níveis de atenção à saúde. Para isso, deve compreender os determinantes sociais, culturais, comportamentais, psicológicos, ecológicos, éticos e legais do processo saúdedoença, nos níveis individual e coletivo ${ }^{1}$.

Tais percepções vão dar origem a diversas proposições de avaliação; dentre elas, a que mais se destacou foi a chamada "pedagogia por objetivos". Esta pedagogia, em oposição à conteudista, roubou a cena e invadiu o ambiente escolar, alardeando suas "verdades" acerca do processo de aquisição de conhecimentos por parte dos indivíduos ${ }^{18}$.

Assim, o professor torna-se sujeito fundamental dessa dinâmica, e precisa enfrentar muitos desafios, sendo o primeiro romper com modelos de ensino tradicionais engessados. Em Odontologia, o profissional não é capacitado para a docência e muitas vezes ficam restritos a técnicas e especializações, reforçando a ideia de quem sabe fazer também sabe ensinar ${ }^{3}$. É necessária mudança no conceito do que é ser professor, ou seja, alguém que proporcione aos alunos não só temas específicos e com alta carga de instrumentalização e que depois testará este conhecimento com provas punitivas de memorização; mas alguém que possibilite aos alunos o conhecimento da sua própria cultura, da postura intelectual que é o modo universitário de situar-se no mundo. O professor deve questionarse constantemente sobre como consegue contribuir para a formação do estudante de ensino superior e a partir deste questionamento buscar aprimoramento pedagógico, por meio de capacitações; refletindo sobre suas ações e, assim, corrigir rotas ${ }^{19}$.

Desde 2013 que a realidade dos professores da FCMS/JF começou a mudar, com a capacitação docente para uma série de metodologias ativas como a problematização, denominada pela instituição como articulação interdisciplinar, na qual o professor é o tutor e trabalha com problemas de papel, cujo o objetivo educacional é realizado por meio de elaboração, pelos acadêmicos, de questões baseadas na taxonomia de Bloom, pertinentes às lacunas do conhecimento do caso e das disciplinas cursadas. Os professores também trabalham com questões para a construção do teste de progresso e do Objective Structured Clinical Examination (OSCE), por exemplo. Entretanto, muitos desafios permanecem, pois essas metodologias exigem muito mais dedicação docente e trabalho em pequenos grupos, o que, consequentemente, implica em mais investimentos e organização estratégia da instituição para que todo o processo possa permanecer de forma efetiva e não somente ser implantado. Assim como os estudantes, o docente deve ser constantemente motivado e orientado, pois o trabalho de metodologias ativas não é somente colocar o discente no centro de seu processo de aprendizagem e deixá-lo seguir sozinho, o que certamente acarretará insegurança e confusão. Pelo contrário, o professor precisa atuar ativamente no apoio a esse discente para que percorra o caminho objetivado. $\mathrm{O}$ que se observa na instituição é uma mudança dos paradigmas culturais do ensinar e aprender, alterando as perspectivas docentes sobre quais são as competências profissionais que devem ser abordadas no ensino e como, de fato, ensinar o estudante a adquiri-las com plena autonomia.

Nesse processo, a construção de uma aprendizagem significativa deve envolver a parceria professor e aluno, sendo necessário um conteúdo potencialmente significativo e a adoção de uma atitude favorável à aprendizagem ${ }^{20}$. Esta última diz respeito à postura discente, que imaturo deve permitir estabelecer associações entre o conhecimento novo adquirido e aqueles já presentes na sua estrutura cognitiva, constituindo o chamado processo de continuidade $^{21}$, que deve ser apresentado e conduzido pelo docente capacitado, com 
paciência e segurança. É como o pensador e psicanalista Rubem Alves defendia:

"O corpo humano só aprende dois tipos de conteúdo: o primeiro, aqueles que dão prazer. $O$ segundo, o meio para chegar ao objeto de prazer. Na sua esmagadora maioria, os conteúdos curriculares nem são objetos de prazer, nem são percebidos pelos alunos como meios para chegar à coisa alguma. O fato é que os alunos não sabem a razão de ter de aprender o que estão sendo forçados a aprender",22.

Nesse cenário, o escritor Paulo Freire dizia ser necessário que superemos a ideia da conta bancária, onde o professor deposita certa quantidade de conteúdos e o aluno apenas os memoriza $^{10}$.

A não realização de um planejamento pedagógico adequado pode levar os docentes a enfrentarem um alto grau de evasão em suas disciplinas, ou mesmo uma ansiedade pessoal ao notarem que seus educandos não estão atingindo o nível de desenvolvimento desejado ${ }^{13}$. O problema "como avaliar esse desenvolvimento?" vem sendo alvo de muitas pesquisas científicas na área de Educação, o que se confirma com o estudo de Bloom e sua equipe, ao demonstrarem que nas mesmas condições de ensino, desconsiderando as variáveis externas ao ambiente educacional, todos os educandos aprendiam, mas se diferenciavam em relação ao nível de profundidade e abstração do conhecimento adquirido ${ }^{23}$. Essa diferença poderia ser caracterizada pelas estratégias utilizadas e pela organização dos processos de aprendizagem para estimular o desenvolvimento cognitivo $^{13}$.

Foi proposto aos professores de Odontologia da FCMS/JF o desafio de padronizar todas as provas aplicadas aos alunos do $1^{\circ}$ ao $8^{\circ}$ períodos, em todas as disciplinas, baseando-se na Taxonomia de Bloom. Sabe-se, pela literatura, que estudantes se sentem angustiados e inseguros quanto às provas confeccionadas por professores individualmente, ou seja, sem o padrão, pois relatam sobre a diferença no modo como se responde a uma questão, dependendo do professor que a construiu $^{23}$, uma vez que uma resposta pode não agradar a dois professores distintos, em uma mesma disciplina, o que configura uma fragilidade no processo avaliativo. Desse modo, fica claro que é imprescindível organizar e estruturar os objetivos instrucionais de forma a direcionar o processo de ensino para a escolha adequada das estratégias e métodos, contribuindo para uma aprendizagem efetiva e duradoura ${ }^{12}$.

Somente padronizar as provas não é o suficiente no processo avaliativo. Como se trata de um novo modelo, os professores precisam ser apoiados e orientados para que possam perceber o desempenho cognitivo do estudante em complexidades mais elevadas. Assim, é importante o papel do NAO, que tem função norteadora docente, ajudando-os na compreensão de como construir itens. Para tanto, além de reuniões coletivas capacitando os docentes sobre questões de prova baseadas na taxonomia de Bloom, reuniões individuais são agendadas durante $o$ semestre para acompanhamento dos processos.

As questões devem ser claras, objetivas, contextualizadas e este contexto deve ter somente itens que são estritamente necessários à construção da resposta. O enunciado deverá permitir uma sequência que estimule o raciocínio lógico com verbos pertinentes à taxonomia da questão. Para que o NAO consiga realizar essa orientação é necessário que o próprio professor responda integralmente sua questão.

Ao receber a meta-avaliação junto com a prova, o estudante passará a compreender o momento avaliativo não só como somativo, mas também formativo, a partir do momento que começa a participar da construção desta 
avaliação. A meta-avaliação envolve apreciação crítica sobre a utilidade, viabilidade, propriedade, precisão, validade e a conduta de uma avaliação para relatar seus pontos fortes e fracos, avaliando sua qualidade, fornecendo orientação e feedback ${ }^{25}$.

Quanto à utilidade, a meta-avaliação deve verificar em que medida os resultados da avaliação estão sendo aproveitados, pois quanto mais os resultados forem usados pelos participantes, mais forte torna-se o atendimento ao critério de utilidade. Assim, é relevante que as questões das provas tenham grande aproximação com a realidade vivida pelo acadêmico em sua prática clínica, sendo útil não só em sua vida acadêmica, mas também profissional ${ }^{26,27}$.

A viabilidade diz respeito ao quanto seria rentável e viável produzir uma meta-avaliação. Nesse caso, a meta-avaliação poderia ser realizada online, evitando assim gastos com impressões, que posteriormente serão digitalizadas para ser entregue aos professores o que a torna duplamente inviável. O critério propriedade se refere ao papel e responsabilidade, por parte dos estudantes, que devem ser éticos e conscientes ao responderem a meta-avaliação.

As informações obtidas dos comentários da meta-avaliação são analisadas pelo NAO quanto ao respeito e termos de baixo calão são removidos antes de encaminhar os documentos ao professor. Entretanto, boa parte dos comentários tem sido construtivos e conscientes. A grande dificuldade da meta-avaliação é o preenchimento adequado dos itens pelos estudantes. A maioria responde "satisfatório" em todos os itens e poucos pontuam o que está insatisfatório e comentam sobre o que pontuou. Isso se deve, provavelmente, pela insegurança quanto ao anonimato, pois entregam a metaavaliação diretamente ao professor, e também pelo cansaço, pois as respondem sempre imediatamente após as provas, que são discursivas e exigem que escrevam muito. Então, quando a prova está boa ou razoável, geralmente respondem "satisfatório" em todos os itens sem tecer qualquer comentário. Quando a prova se apresenta diferente do padrão, com questões fora das taxonomias ou muito confusas, os alunos comentam. Pontualmente, o estudante critica o professor por divergências pessoais ou por não ter se adaptado ainda ao conteúdo da disciplina. Estratégias como tornar a meta-avaliação online, por exemplo, estão sendo trabalhadas pela instituição. Contudo, o determinante para que o estudante valorize a meta-avaliação é o feedback que o NAO oferece, pois quando o acadêmico não obtêm respostas para as angústias relatadas o processo fica ainda mais comprometido.

Já a precisão é a confiabilidade dos resultados da meta-avaliação, na qual o estudante, se familiarizado com o conteúdo, pode avaliar de forma fidedigna, garantindo a veracidade dos resultados obtidos ${ }^{27}$. Dentro desse contexto um possível viés seria o não entendimento do estudante sobre o que é e a importância da meta-avaliação, que ao responder de forma relapsa, contribui para um resultado insatisfatório ao final do processo. A motivação discente deve ser realizada pelos professores em momento próximo ao período das provas, além de análise da perspectiva docente sobre a turma, de como o conteúdo foi abordado, se houve dificuldade ou não, e sobre a própria avaliação. Com o cruzamento dessas informações é possível perceber melhor a realidade sobre a avaliação.

A validade diz respeito à relação entre as conclusões apresentadas pelo discente e suas justificativas ${ }^{28}$. Um exemplo seria a resposta "insatisfatória" do discente em relação ao conteúdo abordado na prova e na disciplina. $\mathrm{O}$ fato de ele ter marcado uma resposta negativa já justifica o questionamento.

Finalmente, a conduta relaciona-se aos padrões legais, éticos e profissionais e se foram respeitados pelo avaliador. Esse critério engloba 
obter consentimento para participar da avaliação e proteção da confidencialidade dos dados e das informações obtidas ${ }^{28}$. Desse modo, a metaavaliação obrigatoriamente é anônima para que não aconteçam retaliações por parte do professor imaturo no processo. Assim, o anonimato e confiabilidade da meta-avaliação são interrelacionados.

Após processada pelo NAO, a metaavaliação é entregue aos professores para reflexão sobre a própria avaliação, considerando a perspectiva de seus alunos. Desta forma, após correção criteriosa das provas, baseada na metaavaliação, os professores fazem uma devolutiva das provas.

Assim, pensando na educação como uma forma libertadora do indivíduo, levando-o a uma prática política, reflexiva, crítica e que permita uma nova lógica da compreensão do mundo, a FCMS/JF encerra o ciclo avaliativo na expectativa de que, a partir dessa dinâmica, os estudantes possam ser melhor avaliados pelos seus professores, tornando esse processo o menos subjetivo possível e mais justo.

\section{CONSIDERAÇÕES FINAIS}

Acredita-se que a elaboração dos instrumentos apresentados conferem à avaliação caráter formativo além do somativo. Esse processo ainda necessita de investimento em capacitações docentes sobre o que é avaliação, seus objetivos na formação discente e como construir itens para avaliar. Além disso, exige dos docentes uma mudança de paradigmas no processo de ensinoaprendizagem, paciência e reflexão com as mudanças, engajamento para transformar os discentes e a si mesmos.

\section{ABSTRACT \\ Cognitive assessment instruments in Dental education: reflections about an experiment}

The cognitive assessment of academic performance in the dental course has been poorly standardized, without obeying a taxonomic order of educational objectives, generating a distorted perception of the competence acquired by the student. Thus, the aim of this study was to present evaluation instruments used in the dental course of School of Medical Sciences and Health of Juiz de Fora (FCMS/JF) to provoke reflections about the dynamics of evaluations. To this end, the Dentistry Assessment Center (NAO) has developed assessment tools for building structured evidence (six discursive questions at three different taxonomy levels), a checklist for verifying assessments by the NAO before being delivered to students and the goal - evaluation, where students evaluate the content of the test, its objectivity and clarity. The three instruments presented in this study form an evaluation dynamic, which are repeated twice per semester, so that there is an improvement in the students' evaluation process and consequently a meaningful learning. Thus, it is believed that these evaluation instruments, within the semiannual dynamics, can contribute to a better perception of cognitive competence acquired by dental students.

Descriptors: Teaching. Institutional Evaluation. Dentistry.

\section{REFERÊNCIAS}

1. Conselho Nacional de Educação. Câmara de Educação Superior. Resolução CNE/CES $\mathrm{n}^{\circ} 3$, de 19 de fevereiro de 2002. Institui Diretrizes Curriculares Nacionais do Curso de Graduação em Odontologia. [Acesso em: 22/03/2017]. Disponível em: http://portal. mec.gov.br/cne/arquivos/pdf/CES032002.p $\underline{\mathrm{df}}$

2. LamersJMS, Baumgarten A, Bitencourt FV, Toassi RFC. Mudanças curriculares na educação superior em Odontologia: inovações, resistências e avanços conquistados. Rev ABENO. 2016; 4:2-18.

3. Ribeiro DM, Rauen MS, Prado ML. O uso da metodologia problematizadora no ensino em Odontologia. Rev Odontol Univ Cid São Paulo. 2007; 19:217-21.

4. Farias PAM, Martin ALAR, Cristo CS. aprendizagem ativa na educação em saúde: percurso histórico e aplicações. Rev Bras Educ Med. 2015. 1: 143-150. 
5. Slavkin HC. The impact of research on the future of dental education: how research and innovation shape dental education and the dental profession. J Dent Educ. 2017; 81(9):eS108-27.

6. Pizzatto E, Garbin CAS, Garbin AJI, Saliba NA. O papel do professor no ensino odontológico. Saúde Debate. 2004; 28 (66):52-7.

7. Aguilar-da-Silva RH, Miguel SS, Teixeira LS. Problematização como método ativo de ensino-aprendizagem: estudantes de farmácia em cenários de prática. Trab Educ Saúde. 2011; 9:77-93.

8. Aguilar-da-Silva RH, Perim GL, Abdalla IG et al. Abordagens pedagógicas e tendências de mudanças nas escolas médicas. Rev Bras Educ Med. 2009; 33:53-62.

9. Garbin CAS, Saliba NA, Moimaz SAS, Santos KT. O papel das universidades na formação de profissionais na área de saúde. Rev ABENO. 2006; 6(1):6-10.

10. Freire P. Pedagogia do Oprimido. São Paulo: Paz e Terra; 1996. P.57-76.

11. Noro LRA, de Santana Farias-Santos BC, Sette-de-Souza PH, Cruz RKS, Pinheiro IAG, Borges REA, et al. O professor (ainda) no centro do processo ensino-aprendizagem em Odontologia. Rev ABENO 2015; 15 (1):2-11.

12. Pinto RS, Melo SPT, Melo P. Metaavaliação: uma década do processo de avaliação institucional do SINAES. Avaliação 2016; 21(1): 89-107.

13. Ferraz APCM, Belhot RV. Taxonomia de Bloom: revisão teórica e apresentação das adequações do instrumento para definição de objetos instrucionais. Gest Prod São Carlos. 2010; 17(2):421-31.

14. Ramirez TV. On pedagogy of personality assessment: application of Bloom's Taxonomy of Educational Objectives. J Person Assess. 2016; 99(2): 146-52.

15. Andriola WB, Araújo AC. Relevância do uso de indicadores de gestão para a autoavaliação e o planejamento estratégico de Instituições de Ensino Superior (IES). Meta: Avaliação. 2016, 8(24): 515-33.

16. Rampazzo SRR. Instrumentos de avaliação: reflexões e possibilidades de uso no processo de ensino e aprendizagem. Londrina. Produção Didático-Pedagógica apresentada ao Programa de Desenvolvimento Educacional. NRE; 2011. [Acesso em: 22/03/2017]. Disponível em: http://www.diaadiaeducacao.pr.gov.br/ portals/cadernospde/pdebusca/producoes_p de/2010/2010_uel_ped_pdp_sandra_regina dos_reis.pdf

17. Amaya MR, Maziero ECS, Grittem L, Cruz EDA. Análise do registro e conteúdo de checklists para cirurgia segura. Esc Anna Nery Enferm. 2015; 19 (2): 246-51.

18. Cupolillo AV Avaliação da aprendizagem escolar e o pensamento de Paulo Freire: algumas aproximações. Práxis Educativa. 2007; 2(1 ): $51-64$.

19. Levites MR, Blasco PG. A Universidade brasileira e a formação humanística do estudante de Medicina. Uma leitura desde o pensamento de John Henry Newman. RBM. 2013; 70: 9-13.

20. Ausubel DP, Novak JD, Hanesian H. Educational psychology: a cognitive view. Holt, Reinhart and Winston, 1978.

21. Mitre SM, Siqueira-Batista R, Girardi-deMendonça JM, Morais-Pinto ND, Meirelles CDAB, Pinto-Porto C, et al. Metodologias ativas de ensino-aprendizagem na formação profissional em saúde: debates atuais. Ciênc Saúde Coletiva. 2008; 13(2): 2133-44.

22. Alves R. Por uma educação romântica. Campinas, SP: Papirus; 2002. P.172.

23. Bloom BS, Hastings JT, Madaus GF. Handbook on formative and summative evaluation of student learning. McGrawHill; 1971.

24. CAED, UFJF. Guia de Elaboração de Itens. Língua Portuguesa. Centro de Políticas Públicas e Avaliação da Educação da Universidade Federal de Juiz de Fora, 2008.

25. Stufflebeam DL. The methodology of metaevaluation as reflected in metaevaluations by the Western Michigan University Evaluation Center. J Person Eval Educ. 2000; 14(1): 95-125.

26. Elliot LG. Meta-avaliação: das abordagens às possibilidades de aplicação. Ensaio: 
Avaliação e Políticas Públicas em evaluation. Sage, 2005.

Educação 2011; 19(73).

27. Ruhe V, Boudreau JD. The 2011 program evaluation standards: A framework for quality in medical education programme evaluations. J Eval Clin Pract. 2012; 19(5): 925-32.

Correspondência para:

Fabiana Aparecida Mayrink de Oliveira e-mail: fabsmay@hotmail.com

28. Davidson EJ. Evaluation methodology Avenida Barão do Rio Branco, 1871/1105 basics: The nuts and bolts of sound 36013-020 Juiz de Fora/MG 